DOI 10.37882/2500-3682.2021.02.20

\title{
ДУХОВНОЕ ВОЗРОЖДЕНИЕ ОБЩЕСТВА ПОСРЕДСТВОМ ФОРМИРОВАНИЯ ТОЛЕРАНТНОГО СОЗНАНИЯ
}

\section{SPIRITUAL REVIVAL OF SOCIETY THROUGH THE FORMATION OF A TOLERANT CONSCIOUSNESS}

\section{E. Morozova}

Summary: The formation of a tolerant consciousness, which is the social norm of the joint life of people and groups with different value orientations, will organically lead society out of spiritual stagnation and make a step from the natural world into the world of spirituality. In the process of spiritual rebirth, humanity must firmly establish in itself moral purity and principles and try to act according to them.

Keywords: spirituality, tolerance, consciousness, society, culture.

\author{
Морозова Елена Николаевна \\ К.п.н., дочент, Учитель, МАОУ «Средняя \\ общеобразовательная школа №12», г. Тобольск \\ elena.morozova.76@mail.ru
}

Аннотация: Формирование толерантного сознания, являющегося социальной нормой совместной жизни людей и групп с разными ценностными ориентациями, позволит органически вывести общество из духовной стагнации и сделать шаг из мира природы в мир духовности. В процессе духовного возрождения человечество должно твердо установить в себе моральную чистоту и принципы и стараться действовать согласно им.

Ключевые слова: духовность, толерантность, сознание, общество, культура.

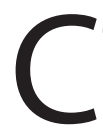
овременная культура будет находиться в стагнации до тех пор, пока она будет строиться с отстраненным и заглохшим, омертвевшим сердцем. Как никогда актуален и жив социологический закон, однажды сформулированный английским философом Т. Гоббсом: «Человек человеку - волк». Австрийский психолог 3. Фрейд также высказывал свое предположение о существовании изначальной враждебности, интолерантности между людьми. Сможет ли кто-либо найти достаточно смелости для того, чтобы, получив печальный жизненные и исторический опыт, поспорить с этим предположением, говорил Фрейд [1, с. 69]. По его мнению, агрессия человека имеет две основные предпосылки. Первая - это данное от рождения стремление к деструктивному началу, или, как он говорил, инстинкт смерти. Вторая это насаждаемые культурными традициями барьеры на пути к удовлетворению своих природных инстинктов. Неверно было бы говорить, что в этом и заключается закон нынешней жизни, но «культурные традиции» заставляют людей обращать на окружающих минимум внимания, дабы не обременять их лишними наблюдениями, умозаключениями и общением. Для каждого человека все окружающие являются просто прохожими. В этом отношении великий русский писатель А.П. Чехов правильно утверждал, что каждый человек для нас является или запертым сундуком, или началом различных недоразумений. По отношению друг другу все люди являются или конкурентами, или соперниками. При этом каждый боится недоброжелательных взглядов других и их неодобрительных замечаний. Люди заботятся друг о друге и проявляются заинтересованность друг в друге только тогда, когда они надеются получить от этого служебную или материальную выгоду. Зачастую ими также руково- дит тщеславие. Добившись от человека своего, его при первой же представившейся возможности предают, причем делают это намеренно, проявляя при этом всю ловкость, на какую способны.

Активизирующийся терроризм, межэтнические и межконфессиональные конфликты, повсеместная агрессия и интолерантность есть суть естественных выражений сердечной жестокости, алчности, зависти, ненависти и неприятия инакомыслия, уже заложенных в бессердечной жизни. К этому привел всеобъемлющий духовный, моральный, общественный и идейный кризис. В нашей стране национальная культура намеренно обеднялась. Вместо того чтобы обеспечить ее органическое развитие, ее ломали, заставляли силой двигаться вперед и всячески искажали, чему в большой степени способствовала идеологическая селекция. Все это привело к разрыву в культурной традиции. Нет ничего странного в том, что все темные стихии оказались в результате на поверхности. Справиться с ними и преодолеть их способно исключительно духовное начало. При его отсутствии люди и не знают о его существовании, и тогда в них пробуждаются звери.

Высоко поднимал планку значимости духовного начала для судеб цивилизации и человека богослов П.А. Флоренский. Стоит только личности, считал он, отказаться от духовности, мгновенно из человека выглянет «звериная морда», рушится духовный стержень - человеческое начало. Неспособность человека противостоять злу без определенного духовного стержня также подчеркивал Э. Фромм - крупнейший мыслитель XX века, один из великой когорты «философов от психологии» и 
духовный лидер Франкфуртской социологической школы: Деструктивное начало представляет собой вторичную возможность, заложенную в самом факте жизнедеятельности людей. Деструктивное начало в человеке характеризуется наличием такой же власти и мощи, как и все остальные страсти человеческие [2, с. 51].

Основная трагедия России - в том, что здесь размываются моральные ценности человека. К сожалению, на протяжении длительного промежутка все нравственные и духовные ценности людей обветшали, ибо оказались никому ненужными. О том, какую огромную роль играет духовное начало, в России вспомнили только тогда, когда оказались на пороге катастрофы. Большинство идеологических начал, навязанных людям за прошлые десятилетия, оказалось замками на песке, несбыточными фантазиями. Немецкому философу и доктору А. Швейцеру удалось идентифицировать социальное заболевание. Так, по его словам, цивилизация, устремившись за материальными ценностями, осталась без своих этических начал, на которых держится общество. По его словам, роковым для современной культуры стал тот факт, что развитие ее материального аспекта проходило гораздо быстрее по сравнению с духовным. Если на первом месте для человека оказывается стремление заполучить материальные ценности, он теряет что-то куда более значимое, превращаясь в ненасытное существо в погоне за призраками, которые, в конечном счете, не делают его счастливее и не позволяют жить полной жизнью. Наказанием за стремление возвести в Абсолют материальное, при котором люди, как выразился философ Н.А. Бердяева, пытается отыскать не смысл жизни, а исключительно блага, которые она может принести, выступают потребительское отношение к жизни и окружающим, все возрастающий эгоизм, ощущение опустошенности. Релятивируя мораль, человек одобряет звериную борьбу за выживание, для войны всех со всеми. Это выводит на передний план среди ценностей бесконечное властолюбие, настолько мощное, что не побоится обратить в «лагерный пепел» целые народы.

Некоторые сейчас говорят о том, что настало «время собирать камни». При этом далеко не все, кто это утверждает, сумели чему-то научиться и сделать важные выводы для себя. Ими по-прежнему движет полное равнодушие, нежелание анализировать, и они только повторяют из раза в раз один и тот же вопрос: для чего копаться в прошлом? Ситуация, которая сложилась на сегодняшний день, вынуждает человечество посмотреть назад. Если забыть то зло, которое было в прошлом, и уж тем более стремиться найти ему оправдание, - это то же самое, что пытаться вернуть его назад. Разобраться в прошлом, дать оценку совершенному злу просто необходимо, так как его история живет в нашем сознании. Успешность решения поставленной задачи будет зависеть от умения общества руководствоваться в своей повседнев- ной деятельности главным принципом существования, провозглашенным еще древне-греческим философом Сократом: «Познай самого себя». Тем самым человечество сделает шаг из мира природы в мир духа. Философ считал, что внутренний мир индивида является дверьми в мир объективных законов духовной жизни, которая стоит выше всего земного. Познание самого себя должно стать одной из обязанностей человека перед самим собой, так как обязанности перед самим собой, по словам немецкого философа И. Канта, суть верховное условие и начало всякой нравственности. Идя по этому пути, нам необходимо суметь распоряжаться собой таким образом, чтобы уметь соблюдать все нравственные обязательства. Это послужит стимулом для утверждения в своем сознании и своей душе нравственной чистоты и принципов и стремления поступать, руководствуясь ими [3, с. 127]. Лишь в этом случае будут основания утверждать, что человек выполнил всеобщую обязанность прежде всего перед самим собой.

Человек приходит в мир из мрака, он ничего не может разглядеть вокруг. Ребенок. Придя в этот мир, только со временем начинает замечать то, что его окружает. Однако ощущение, что ты являешься одним-единственным огнем, освещающим темноту и мрак, не проходит до конца. «Я» всю жизнь выступает в качестве основы жизнедеятельности человека. В нем заключаются корни и источники человеческой самости, склонности к эгоцентризму и стремлением к отчуждению и внутреннему уединению. Понятно, что огромная доля правды содержится в утверждении, что мы способны осознать абсолютизированную ценность собственного «Я». По справедливому утверждению французского философа и теолога П. Тейяра де Шардена, персонализация, возникновение самосознания личности представляют собой наивысшую ступень эволюции. В каждом человеке заложены предпосылки для и свободы творческое начало. Это же способствует появлению демаркационной границы между личностью и биосферой. Однако человека всю жизнь преследует множество угроз, таких как стагнация и риск остаться на уровне развития ребенка, который мнит себя ядром всего мироздания. Подобные проявления инфантилизма самости возводит высокие стены вокруг человеческого «Я», в результате чего реальные контакты становятся весьма осложненными, а зачастую и вовсе невозможными. Однако если личность сможет сломать эту крепость собственного «я», у него может появиться комплекс фальшивого самоутверждения своей личности.

По словам французского физика, математика и философа Б. Паскаля, каждое «Я» стремится созерцать свое величие, однако понимает свою незначительность; мечтает стать счастливым, но на деле глубоко несчастно; желает быть идеальным, но в реальности несовершенно. Преодоление таких противоречий, по мнению Паскаля, 
заключается в том, чтобы соблюдать Евангелие, призывающее отвергнуть самого себя, собственную самость свою. При преодолении самости на помощь приходит любовь. Как говорил отечественный религиозный философ В.С. Соловьев, сущность любви заключается в том, что благодаря ей человек всем своим существом утверждает за другим человеком ту безусловную центральную роль, которую в связи со своим безграничным эгоизмом мы признаем лишь в себе. Только любовь имеет достаточно силы для реализации настоящего контакта. Это работает не только в человеческих взаимоотношениях между людьми, но и играет роль в отношении человека к Бытию, позволяет представить и постичь страдание другого человека [4, с.157].

На основополагающее значение любви в трансформации жизни человека указывал и Эрих Фромм. Он говорил, что лишь в случае, когда в основе взаимоотношений человека с другими людьми лежат принципы любви, он испытывает ощущение духовного единения с ними и при этом может сохранить свою внутреннюю целостность. Только созидательное начало в человеке может помочь ему начать идентифицировать себя с природой, сливаясь с ней и при этом, не исчезая в ней без следа. Умение любить, наличие созидательного начала, способность преодолеть кровосмесительную привязанность к своему народу и родной земле, ощущение единства, в основе которого лежит восприятие собственного «Я» как субъекта, воплощающего собственные способности, восприятие действительности в отрыве от этого «Я», т.е. умение быть рациональным и объективным, полагает Фромм, и являются теми свойствами, которые указывают на психологическое здоровье конкретного социума [2, c. 78].

Рассматривая моральное, физическое и психологическое выздоровление социума при помощи любви, следует учитывать, что такую трансформацию можно реализовать исключительно во внутренней духовной работе личности, так как чувство любви не может зародиться и стать одухотворенным пожеланию других людей. Духовное начало так же может прорасти и исполниться светом лишь при продолжительном моральном духовном очищении. В основу выхода из затянувшегося нравственного банкротства должны быть положены взаимопонимание, терпимость и диалог, а эффективность этого пути во многом будет зависеть от уровня осознания и принятия толерантности как неотъемлемой составляющей системы ценностей современного общества, а также готовности руководствоваться этим понятием в повседневной деятельности.

Следует привести резолюцию № 5.61 Генеральной Конференции ЮНЕСКО от 16.11.1995 года. В ней, в частности, говорится, что под толерантностью подразумевается способность уважать, понимать и правильно от- носиться ко всему культурному многообразию планеты, всех видов самовыражения и методов выражения индивидуальности личности $<\ldots$. . Речь идет не просто о нравственной обязанности, но и о правовой и политической необходимости. Толерантность представляет собой добродетель, благодаря которой можно достичь мира и искоренить войну, приведя в качестве альтернативы культуру мира, пацифизм. В документе отмечается также, что толерантность следует рассматривать в первую очередь в качестве активного отношения, при котором человек признает все права и главные свободы других людей [5, с. 299].

Знаменитым культурологом и этнографом С.А. Арутюновым, не без печальной иронии, были сказаны слова по поводу толерантности, представляющей собой социальную норму человеческого общежития, в котором живут люди и их объединения, имеющие разные аксиологические ориентиры. По его словам, толерантность является мифическим существом. [6, с. 8-17].

В развитие этой идеи французским философом П. Тейяром де Шарденом было выдвинуто сравнение всего человечества с деревом, отдельные ветки которого - это разные этносы, населяющие планету. По его словам это не естественно, когда одна ветка пытается забрать у дерева все его соки и вырастает за счет гибель остальных веток, ведь для того чтобы получить солнечное тепло, дереву нужно, чтобы вся его крона росла равномерно. Это работает и с человечеством, для которого дверь в светлое будущее может открыться только под напором всего человечества в целом [7, с. 194].

Об опасном результате противостояния разных этносов говорил и философ из Англии Б. Рассел. В частности, он подчеркивал, что важно выйти на новый уровень мышления и озаботиться предотвращением всех противостояний и войн между людьми разных национальностей. Он утверждал, цивилизация может пойти двумя путями в своем развитии. Первый - это мир, обеспеченный с помощью соглашений и договоров, второй - это гибель человечества [8, с. 132]. Об этом же предостерегал в свое время и политолог из США Л. Пирсон. По его словам, цивилизация приближается к тому моменту, когда разные народы смогут сосуществовать мирно, передавая друг другу свою культуру и исторический опыт, способствуя взаимообогащению друг друга. Если же этого не произойдет, то наша небольшая переполненная людьми планета станет местом войн, непонимания, противостояния и всевозможных катастроф [9, с. 532].

Человеку трудно привить миролюбие против его воли, и человечество по своему опыту знает, к чему приводит стремление искусственным путем вселить в сознание людей мысли о всеобщем счастье и благополучии. Опыт, при котором мысли о толерантности будут приви- 
ваться людям против их воли, обречены на провал. Фраза «принудительно-добровольное миролюбие» является оксюмороном. Никого нельзя вынудить стать толерантным, а равно невозможно изменить особенности менталитета, реформировать духовную сферу в соответствии с запросами эпохи.

Вполне вероятно, что человек с энтузиазмом и интересов будет слушать все самые сильные аргументы в пользу толерантности и уважительного отношения к мнению других людей. Возможно, человек даже согласится, что именно эти действия помогут устранить злобу и ненависть в современном социуме, искоренить напряженность, благодаря чему он и сам сможет ощущать себя безопасно и спокойно. Человек вполне может принять эту точку зрения. однако в обстоятельствах, исключающих возможность размышлять и подразумевающих необходимость действовать, он все равно отдаст предпочтение традиционно сложившейся модели поведения.

С учетом психологической специфики поведения индивида по отношению к внешней действительности мы заключили, что ориентированность на выработку на толерантности в обществе является больше не рациональным, а волевым поступком. Он находит свое выражение в конкретных действиях, а не в пространных размышлениях по этому поводу.

Однако каким образом может быть сформирована такая волевая установка? В чем заключается природа и сущность глубинных механизмов привития толерантного мышления? Приведем произведение «Пир», написанное древнегреческим философом-идеалистом Платоном. В этом произведении Аристофан, являющийся героем одного из диалогов, рассказывает легенду миф об андрогинах. Андрогины были особенными созданиями: у них была округлая форма, они были рождены с четырьмя ногами, четырьмя руками и двумя лицами. Боги испугались их силы и разделили их на две половины. Каждая половина, исполнившись вожделения, направилась ко второй с ощущением собственной неполноценности. Не вдаваясь глубоко в тему полов, можно сказать, что в этой легенде очень хорошо отражается ключевая установка миролюбивого разума. В частности, необходимо относиться к самому себе как несовершенному созданию, которое открыто для опыта того, для кого такой опыт стал основополагающим и помог принять и понять собственное единство и целостность.

По мере того как целостность человека вырабатывается, выступая фундаментом миролюбивого сознания, большое значение отводится тщательному, углубленному исследованию факторов возникновения негативных проявлений (НП), присутствующих во всех этносах и культурах. Обнаружение и восприятие негативных проявлений обеспечивает поступательное формирова- ние толерантного сознания (под которым мы подразумеваем способность признать наличие многообразия культур, каждой из которых свойственны свои преимущества и отрицательные качества, множественность взглядов, являющаяся неизбежной и даже необходимой, так как именно на ней основывается в настоящее время воспитательный процесс; кроме того, именно эта множественность представляет собой ценность и общественную норму в каждом гражданском обществе, имеющем право на то, чтобы быть разным), а также по отношению ко всему отличному от привычного, тем более характеризующемуся отрицательной коннотацией. Это достигается несколькими путями:

- принять многообразие культур и то, что негативные проявления существуют во всех народах и их культурах;

- разобраться в причинах наличия негативных проявлений в иерархически устроенных культурах других народов;

- выяснить, осознают ли представители других национальностей собственные негативные проявления;

- принять точку зрения, что нельзя говорить о традициях и обычаях других народностей исходя из собственной аксиологической системы;

- необходимо понять и принять, что все имеющие место конфессии наделены абсолютно равными правами;

- - следует сформировать условия, которые позволят дать человеку понять, что он полон предубеждений;

- важно развить стремление к трансформации собственных укоренившихся взглядов, принимая ценности культурного многообразия и утверждая позитивное начало в этом многообразии и пр.;

- следует распространять позитивные коннотации, которые позволяют использовать сведений, не подтверждающие изначально сформировавшиеся стереотипы относительно других народов;

- важно владеть собственными когнитивными средствами;

- следует прививать окружающим тактику противостояния механическим реакциям на стереотипы, которые зарождаются на подсознательном уровне; это позволит развить гибкость подобных стереотипов, в отношении которых достаточно сложно применять волевой контроль;

- следует сплачивать индивидов вокруг единых целей; это позволит перенести акцент с этноцентризма на межличностное взаимодействие;

- необходимо сформировать условия, которые помогут человеку быть уверенным в позитивных началах собственной культуры. Это даст возможность ослабления воздействия механизма психологической защиты от окружающих, выливающейся во враждебное отношение к окружающим. 
Также это позволит исключить возможность легитимного влияния психических механизмов каузальной атрибуции в коммуникации и взаимоотношениях существующих культур и народов;

- следует нарастить межличностные связи, понимая, что свои и посторонние имеют много общего; это позволит трансформировать отношение к роли социальных групп при разделении людей. Это, в свою очередь, обеспечит персонализацию и декатегоризацию;

- следует активировать общественное сознание для того, чтобы определить уровень сегрегации и валентности как латентной пассивной разновидности интолерантности, инструмента нивелирования значимости взаимодействия с представителями других культур, и подробно разъяснить последствия этой формы разрешения вопросов взаимодействия между представителями разных культур.

Из сказанного можно заключить, что выработка толерантного менталитета человека должна рассматриваться в качестве общественно-психологических факторов сохранности культур (это помогает людям обрести личные смыслы) и плюрализма культур (благодаря чему сможет выжить вся социальная структура), потому что это выживание основано на мире и межнациональной толерантности.

В 1918 г. отечественный философ Н.А. Бердяев гово- рил о том, что можно стремиться к близости и духовному единству всех этносов. Однако невозможно стремиться к тому, чтобы таким способом были уничтожены национальные образы и культуры. Подобные устремления означают желание погасить целую вселенную культурных богатств. Культура не может являться человеческой в отрыве от человека, так как она всегда неразрывно с ним связана: она является человеческой, народной, индивидуально национальной. И только в этом понимании она может восходить до общественности $[10$, с. 56].

По словам Ф.М. Достоевского, человеку дана свобода, однако в ней ему также предоставлена способность творить великие дела и чинить подлости, нести добро или сеять зло. При этом. По словам писателя, личность не обязана проявлять гуманность, однако она может нести эту гуманность в себе. Каждый сам идет по своей дороге духовного развития или разрушения [11, с. 83]. То, какую дорогу выберет индивид, зависит от его мудрости. Ведь только мудрость, по словам отечественного доктора и учителя П.Ф. Лесгафта, способна открыть человеку глаза на узость собственной жизни, указав при этом на важность общественных проявлений. Это поможет человеку понять, что его святая обязанность состоит в содействии поступательному развитию социума, в котором он живет. Ведь социум, как утверждал В.С. Соловьев, представляет собой дополненную либо расширенную личность, а в каждой личности происходит отражение сжатого либо концентрированного социума.

\section{ЛИТЕРАТУРА}

1. Freud S. Civilization and Its Discontents. Translated from the German by J. Riviere. The Hogarth Press, Ltd. London, 1953.

2. Фромм Э. Здоровое общество. М.: Хранитель, 2006.

3. Кант И. Лекции по этике. М.: Республика, 2005.

4. Соловьев В.С. Сочинения в двух томах. М.: Мысль, 1988.

5. Реформа и развитие высшего образования. Париж: ЮНЕСКО, 1995. С. 299.

6. Нравственность и политика // Собрание сочинений. Брюссель, 1996. Т. 5. С. 8-17

7. Тейяр де Шарден П. Феномен человека. М., 1987.

8. Рассел Б. Человечество в опасности // Вопросы философии. 1988. № 5. С. 131-133.

9. Хантингтон С. Столкновение цивилизаций. М.: АСТ, 2003.

10. Бердяев Н.А. Судьба России. М.: Мысль, 1990.

11. Достоевский Ф.М. Политическое завещание: Сб. статей за 1861-1881 гг. М.: Алгоритм, 2006.

○ Морозова Елена Николаевна (elena.morozova.76@mail.ru). Журнал «Современная наука: актуальные проблемы теории и практики» 